\title{
Oportunidades e desafios no ensino superior: experiências de universitários de camadas populares da Universidade Federal de Ouro Preto
}

\author{
Mariza Aparecida Costa Pena ${ }^{1}$ \\ Rosa Maria da Exaltação Coutrim ${ }^{2}$ \\ Daniel Abud Seabra Matos ${ }^{3}$
}

\section{Resumo}

Esse artigo apresenta resultados de entrevistas com universitários cotistas, de baixa renda, ingressantes no início de 2013 em cursos prestigiosos da Universidade Federal de Ouro Preto. Para as entrevistas foram selecionados seis estudantes de baixa renda, pertencentes aos cursos de Medicina, Direito e Engenharia Civil. À luz da Sociologia da Educação, buscou-se nos relatos, compreender as condições de acesso e permanência, e conhecer as experiências, oportunidades e desafios dos cotistas de baixa renda na graduação. Os depoimentos revelaram que, embora enfrentem dificuldades financeiras, acadêmicas e de sociabilidade principalmente no início do curso, esses jovens apresentam disposições que culminam em oportunidades de crescimentos acadêmico, pessoal e profissional. Palavras-chave: Percurso Universitário; Camadas Populares; Ação Afirmativa; Longevidade Escolar.

Opportunities and challenges in higher education: experiences of undergraduate students of the Universidade Federal de Ouro Preto

\begin{abstract}
This article presents the results of interviews with low-income university students, who were enrolled at the beginning of 2013 in prestigious courses at the Federal University of Ouro Preto. For the interviews were selected six students of low income, belonging to the courses of Medicine, Law and Civil Engineering. In the light of the Sociology of Education, we sought to understand the conditions of access and permanence, and to know the experiences, opportunities and challenges of low-income students in undergraduate studies. The testimonies revealed that, while facing financial, academic and sociability difficulties especially at the beginning of the course, these young people present dispositions that culminate in academic, personal and professional growth opportunities.

Keywords: University Course; Popular Layers; Affirmative Action; School Longevity.
\end{abstract}

\section{Introdução}

As instituições públicas de Ensino Superior têm vivenciado mudanças significativas, principalmente em relação à composição do seu corpo discente, que passou a ser constituído por uma diversidade cultural, social e econômica, nunca vista na história da Educação Superior

\footnotetext{
${ }^{1}$ Universidade Federal de Ouro Preto - Escola de Medicina - Ouro Preto, MG - E-mail: mariza.penna@ufop.edu.br.

${ }^{2}$ Universidade Federal de Ouro Preto - Instituto de Ciências Humanas e Sociais - Departamento de Educação - Mariana, MG - E-mail: rosacoutrim@ufop.edu.br.

${ }^{3}$ Universidade Federal de Ouro Preto - Instituto de Ciências Humanas e Sociais - Departamento de Educação - Mariana, MG - E-mail: danielmatos@ufop.edu.br.
} 
brasileira, graças às políticas educacionais implementadas nas últimas décadas. Figuram entre as principais políticas visando a democratização do acesso e da permanência no nível superior de ensino, o Programa de Reestruturação e Expansão das Instituições Federais de Ensino Superior (REUNI - Decreto no 6.096, de 24/04/2007), o Sistema de Seleção Unificada (SiSU - Portaria Normativa MEC no 2, de 26/01/2010) e a Política de Ação Afirmativa, regida pela Lei 12.711, instituída em 29 de agosto de 2012 (BRASIL, 2012).

A referida Lei de Cotas exige que as instituições públicas de ensino superior (IPES), por meio do SiSU, reservem pelo menos $50 \%$ de suas vagas para egressos de escolas públicas e desse montante, estratifica-se um percentual de vagas de acordo com a renda e o pertencimento a grupos étnico-raciais (pretos, pardos e indígenas), e, a partir de 2017, passa a contemplar também as pessoas com deficiência (BRASIL, 2016).

Embora apresente algumas fragilidades (COUTRIM; PENA; SOUZA, 2018), a maioria das IPES brasileiras adota essa política, proporcionando alterações profundas no meio universitário e na vida de muitos jovens, especialmente daqueles oriundos de meios socioeconomicamente desfavorecidos, cujo percurso acadêmico, segundo estudos realizados no âmbito da Sociologia da Educação (BOURDIEU; CHAMPAGNE, 2013; PORTES; SOUZA, 2013; PORTES, 2014; PIOTTO, 2007, 2014; PIOTTO; ALVES, 2016), é considerado atípico e na maioria das vezes marcado pelas desigualdades de oportunidades.

Estar numa universidade pública, para estudantes de baixa renda, implica participar de novas experiências e desafios. Na maioria das vezes, esses estudantes enfrentarão um ambiente completamente desconhecido e diverso ao que estavam acostumados e terão que passar pelo processo de "estranhamento" e de "aprendizagem", até adquirirem o status de estudante universitário, que significa "afiliar-se a um novo status social" (COULON, 2008, p.31). O contraste entre a realidade do mundo universitário e a dos estudantes pobres pode afetar o convívio social, principalmente no início do curso, aflorando, nesses indivíduos, o sentimento de não pertencimento àquele lugar, podendo resultar em solidão e isolamento (PIOTTO, 2007, 2014; SOUZA, 2009). Outros estudiosos, como Portes (2001), acreditam que, além das necessidades materiais, o distanciamento desses estudantes da cultura valorizada no meio universitário (artes, fotografia, jornal, revista, teatro, cinema, concertos, esporte etc.) pode provocar uma forte angústia, o que muitas vezes requer cuidados pedagógicos, psicológicos e até psiquiátricos. 
Por outro lado, essas desigualdades sociais podem ser propulsoras de crescimento pessoal, na maioria das vezes, graças à mobilização familiar, à intervenção de terceiros, como: professores, amigos ou vizinhos, grupos religiosos, ou outros grupos de relacionamento, como: esporte, trabalho etc. (SOUZA, 2009, 2014). Cabe ressaltar, também, o empenho do próprio estudante na construção de seu percurso escolar. Em seus estudos, Lacerda (2006) destaca a autonomia, a superação, a perseverança, a dedicação aos estudos, o respeito às normas acadêmicas e a competição, como disposições que permitiram a esses indivíduos a condição privilegiada de estarem numa universidade. As precariedades econômicas e o fraco capital cultural, segundo Portes (2001), Lacerda (2006) e SOUZA (2009), tornam necessário um sobreesforço e uma autodeterminação desses estudantes para continuarem os estudos.

Na perspectiva de Viana (2009), a presença das famílias pertencentes aos estratos inferiores na escolarização dos filhos se faz de forma diferenciada das camadas médias, e não pode ser considerada omissa. Encaminhar os filhos à escola, exigir bom desempenho, liberar o filho do trabalho para que possa se dedicar aos estudos, controlar as amizades, entre outras, são ações empreendidas pelas famílias populares no processo de escolarização dos filhos, que podem fazer a diferença em seus percursos escolares. Ou seja, os destinos escolares podem ser definidos a partir das diferenças intrínsecas no cotidiano familiar. Para Lahire (1997, p.27), “o aluno que vive em um universo doméstico material e temporalmente ordenado, adquire, portanto, sem o perceber, métodos de organização, estruturas cognitivas ordenadas e predispostas a funcionar como estruturas de ordenação do mundo".

Lahire (1997) considera que a "ordem moral doméstica" é responsável pela criação de um ambiente ordenado e pela inculcação de valores que refletem o desenvolvimento e obediência às regras e normas e pode ser verificada no respeito ao professor e às normas escolares, no acompanhamento do rendimento escolar dos filhos pela família, na definição dos horários para os estudos e o lazer, nas relações de amizade e situações de socialização, constituindo um ambiente propício para a obtenção de bons resultados escolares. Além disso, a estabilidade na configuração familiar e a influência de eventos como separações, mortes, desemprego etc., podem impactar no desenvolvimento escolar do indivíduo (LAHIRE, 1997).

Em suma, o percurso escolar nas camadas populares é resultado de um processo de socialização e de uma combinação complexa de fatores estruturais, familiares e pessoais, 
conforme comprovado nos estudos de Nogueira (2011), Portes, Lopes e Silva (2011); Portes e Sousa (2013) e Setton (2012).

Nesse sentido, esse estudo ${ }^{4}$ teve como objetivo principal investigar o percurso universitário de estudantes cotistas após o ingresso em cursos de graduação presenciais de alto prestígio de uma instituição pública de ensino superior.

A proposta teórico-metodológica se apoiou principalmente nos estudos advindos da Sociologia da Educação, tendo como pilares os estudos de Viana (1998, 2009); Portes (2001, 2014) e Piotto (2014, 2016) especialmente, no que se refere à discussão sobre acesso, permanência e experiências universitárias nos meios populares.

\section{Metodologia}

Esse artigo originou-se de uma pesquisa desenvolvida com estudantes cotistas, de baixa renda, que ingressaram em cursos presenciais de graduação da Universidade Federal de Ouro Preto (UFOP), no primeiro período letivo de 2013, e realizada em duas etapas, sob abordagem mista quantitativa-qualitativa.

Na primeira etapa de cunho quantitativo, verificou-se o nível socioeconômico (NSE) dos cursos da UFOP (RODRIGUES et al., 2017), e, por meio das informações disponibilizadas pelas Pró-Reitorias de Graduação (PROGRAD) e de Assuntos Comunitários e Estudantis (PRACE) da UFOP, foi feito um levantamento das características acadêmicas dos estudantes cotistas ingressantes em 2013/1 e de sua participação em atividades extracurriculares (programas de monitoria, proativa, iniciação científica, mobilidade acadêmica etc.). Foram selecionados seis cursos, de acordo com o NSE e a área de conhecimento (Ciências da Saúde, Ciência Sociais Aplicadas e Engenharias), sendo em cada área selecionado um curso com alunos de maior NSE (Medicina, Direito e Engenharia Civil) e o outro com alunos de menor NSE (Nutrição, Serviço Social e Engenharia de Computação). Nessa etapa, comprovou-se estatisticamente que, ao longo do curso de graduação, os estudantes cotistas alcançam aproveitamento acadêmico semelhante aos alunos da ampla concorrência, embora os estudantes cotistas tenham menor desempenho médio na entrada da Universidade por meio do ENEM.

\footnotetext{
${ }^{4}$ Este trabalho é fruto de dissertação. 
Na segunda etapa qualitativa, foram realizadas entrevistas, cujos resultados expomos nesse artigo. Para essa etapa, foram selecionados os três cursos de maior NSE, analisados na abordagem quantitativa: Medicina, Direito e Engenharia Civil. Segundo Pena (2017, p.30), “os cursos mais elitizados são também os cursos de maior prestígio social e os mais concorridos, e por consequência são, provavelmente, os que demandam maior esforço do estudante cotista para ingressar e permanecer na universidade". Para as entrevistas, a princípio, foram selecionados dois estudantes cotistas, de baixa renda, de cada um dos cursos analisados nessa etapa. Assim, entrevistamos no total seis alunos. Quase no final da pesquisa, houve uma desistência de participação. Considerando a escassez do tempo e a falta de estudantes que atendessem aos critérios socioeconômicos de escolha dos sujeitos para as entrevistas, visando minorar possíveis prejuízos aos resultados, optamos por selecionar uma estudante de baixa renda, que ingressou no curso de Direito pelo processo de reopção (transferência interna entre cursos), em 2014. A participação na entrevista foi voluntária e os depoimentos aconteceram em horários e datas diferentes, de acordo com a disponibilidade de cada participante. Todos os cuidados éticos foram tomados para a garantia do sigilo das informações e da integridade do participante e o Termo de Consentimento Livre e Esclarecido (TCLE), com o intuito de obter o aceite de participação na pesquisa, bem como autorização para a gravação das entrevistas e posterior utilização dos dados para fins científicos, foi devidamente assinado, conforme recomendado pelo comitê de ética da UFOP (CAAE 51056215.3.0000.5150, Parecer no . 1.408.829). Foram utilizados pseudônimos para evitar a identificação dos participantes.

As entrevistas interpretativas (SZYMANSKI, 2002), possibilitaram conhecer um pouco da vida familiar e escolar pregressa dos depoentes e revelaram elementos que contribuíram para a longevidade escolar e suas experiências universitárias. Para orientar a construção e análises dos dados, foram definidas as seguintes categorias: perfil dos entrevistados, percurso escolar e experiências universitárias. Essas categorias foram definidas visando encontrar respostas para os seguintes questionamentos: Como tem se constituído o percurso universitário dos estudantes da UFOP ingressantes pela política de ação afirmativa? Que fatores contribuíram para o ingresso e a permanência dos estudantes de estratos populares que estudam na universidade? Os ingressantes pela ação afirmativa participam das mesmas atividades universitárias e possuem as mesmas oportunidades dos demais estudantes? Que desafios são impostos aos ingressantes pelas cotas? 


\section{Resultados e discussões}

\section{O perfil dos entrevistados}

Considerando as informações extraídas do banco de dados da PROGRAD e da PRACE pode-se identificar algumas características dos estudantes entrevistados, conforme apresentado no Quadro 1.

Quadro 1: Perfil dos estudantes da Universidade Federal de Ouro Preto entrevistados

\begin{tabular}{|c|c|c|c|c|c|c|}
\hline \multicolumn{7}{|c|}{ DADOS GERAIS DOS ENTREVISTADOS } \\
\hline Pseudônimo & Gabriela & José & Sofia & Henrique & Pedro & Camila \\
\hline Curso & $\begin{array}{c}\text { Engenharia } \\
\text { Civil }\end{array}$ & $\begin{array}{l}\text { Engenharia } \\
\text { Civil }\end{array}$ & Direito & Direito & Medicina & Medicina \\
\hline $\begin{array}{l}\text { Idade de } \\
\text { ingresso } \\
\text { (maio/2013) }\end{array}$ & 19,9 & 17,9 & 19,9 & 24 & 28,7 & 22,5 \\
\hline $\begin{array}{l}\text { Cor/raça } \\
\text { autodeclarada }\end{array}$ & Parda & Branco & Preta & Branco & Pardo & Parda \\
\hline Gênero & Feminino & Masculino & Feminino & Masculino & Masculino & Feminino \\
\hline Estado civil & Solteira & Solteiro & Solteira & Solteiro & Solteiro & União estável \\
\hline $\begin{array}{l}\text { Cidade/UF } \\
\text { familiar }\end{array}$ & $\begin{array}{c}\text { Belo } \\
\text { Horizonte/MG }\end{array}$ & Mariana/MG & $\begin{array}{c}\text { Ouro } \\
\text { Preto/MG }\end{array}$ & Extrema/MG & $\begin{array}{c}\text { Belo } \\
\text { Horizonte/MG }\end{array}$ & $\begin{array}{c}\text { São José da } \\
\text { Lapa/MG }\end{array}$ \\
\hline $\begin{array}{l}\text { Instituição em } \\
\text { que concluiu } \\
\text { o Ensino } \\
\text { Médio }\end{array}$ & $\begin{array}{l}\text { Instituto } \\
\text { Federal }\end{array}$ & $\begin{array}{c}\text { Escola } \\
\text { Municipal }\end{array}$ & $\begin{array}{l}\text { Escola } \\
\text { Estadual }\end{array}$ & $\begin{array}{l}\text { Escola } \\
\text { Estadual }\end{array}$ & $\begin{array}{l}\text { Escola } \\
\text { Estadual }\end{array}$ & $\begin{array}{l}\text { Colégio } \\
\text { Técnico }\end{array}$ \\
\hline $\begin{array}{l}\text { Ano } \\
\text { conclusão do } \\
\text { Ensino Médio }\end{array}$ & 2012 & 2012 & 2011 & 2007 & 2002 & 2009 \\
\hline $\begin{array}{l}\text { Cidade/UF da } \\
\text { instituição de } \\
\text { Ensino Médio }\end{array}$ & $\begin{array}{c}\text { Ouro } \\
\text { Preto/MG }\end{array}$ & Mariana/MG & $\begin{array}{c}\text { Ouro } \\
\text { Preto/MG }\end{array}$ & Cambuí/MG & Contagem/MG & $\begin{array}{c}\text { Belo } \\
\text { Horizonte/MG }\end{array}$ \\
\hline Nota ENEM & 636,3 & 717,0 & 535,6 & 661,5 & 756,2 & 757,9 \\
\hline $\mathrm{NSE}^{5}$ & $\begin{array}{c}3,2 \\
\text { (Mais baixo) }\end{array}$ & $\begin{array}{c}4,1 \\
\text { (Baixo) }\end{array}$ & $\begin{array}{c}3,2 \\
\text { (Mais } \\
\text { baixo) } \\
\end{array}$ & $\begin{array}{c}3,4 \\
\text { (Mais baixo) }\end{array}$ & $\begin{array}{c}2,9 \\
\text { (Mais baixo) }\end{array}$ & $\begin{array}{c}3,1 \\
\text { (Mais baixo) }\end{array}$ \\
\hline $\begin{array}{l}\text { Coeficiente de } \\
\text { rendimento } \\
\text { escolar anual } \\
\text { (2013 a 2016) }\end{array}$ & 5,4 & 8,3 & 6,4 & 7,6 & 7,4 & 7,9 \\
\hline Repetência & 18 & 0 & 10 & 1 & 0 & 0 \\
\hline
\end{tabular}

${ }^{5}$ O NSE é uma variável latente, que pode ser definida como uma síntese feita a partir da combinação de vários elementos (RODRIGUES et al., 2017, p.4). O NSE dos estudantes pesquisados foi calculado em uma escala de 0 a 10, que, posteriormente, foi separada em sete faixas: 1 - "Mais baixo": 0 a 3,39; 2 - "Baixo": 3,40 a 4,26;3 - "Médio baixo": 4,27 a 4,91;4 - "Médio": 4,92 a 5,52;5 - “Médio alto": 5,53 a 6,26; 6 - “Alto": 6,27 a 7,14;7 - "Mais alto": 7,15 a 10,00.

Periódico Horizontes - USF - Itatiba, SP - Brasil - e021010 
DADOS GERAIS DOS ENTREVISTADOS

\begin{tabular}{l|l|l|l|l|l|l}
\hline Pseudônimo & Gabriela & José & Sofia & Henrique & Pedro & Camila \\
\hline por nota & & & & & & \\
\hline
\end{tabular}

Fonte: Elaborado pelos autores.

A partir desses dados, pode-se verificar que a maioria dos estudantes entrevistados era parda, solteira e pertencia ao NSE "mais baixo". Entre os estudantes entrevistados, embora todos tenham ingressado com idade ideal na educação básica, apenas um deles ingressou com idade ideal no ensino superior (até 18 anos). O Censo da Educação Superior 2010 (INEP, 2012) explica que são os estudantes com menor NSE os que mais ingressam tardiamente no Ensino Superior (faixa de 25 anos ou mais), devido a atrasos na educação básica, qualidade do ensino público, necessidade de cursos preparatórios, ou interrupções nos estudos gerados pela necessidade de trabalho (PORTES, 2014). No que diz respeito à origem geográfica, todos os estudantes entrevistados são do estado de Minas Gerais, sendo grande parte proveniente de Belo Horizonte e proximidades.

Por meio dos relatos, verificou-se, ainda, que a maioria dos entrevistados provém de núcleo familiar pequeno, composto por, no máximo, três filhos e os níveis de escolarização das famílias são baixos. O grupo das mães apresentou maior escolaridade, entre as quais duas possuem pós-graduação, os pais concluíram no máximo o Ensino Fundamental e somente os avós maternos de Henrique concluíram o Ensino Fundamental.

Questão de oportunidade, porque, por exemplo, os meus avós maternos eles são da roça. Então minha mãe desde pequena começou a trabalhar na roça, e com onze anos de idade que ela foi fazer a primeira série. Então assim, ela formou bem mais velha né, e só conseguiu chegar até a oitava série. E antigamente também as pessoas não ligavam muito pra isso. Existiam professores, igual eu tenho uma tia, que ela era professora, e só tinha quarta série. Aí agora não. Agora até pra você ter um serviço assim, por exemplo, de gari, você tem que ter o Ensino Médio. Aí eu acho que as pessoas estão correndo mais atrás do estudo por essa questão. [...] Eu tenho uma tia, que ela é formada em história, é professora de história, e uma prima que faz psicologia, só. Os outros todos trabalham assim, normal, sem escolaridade (Gabriela, 60 período, Engenharia Civil).

A baixa escolaridade dos antecessores desses estudantes nos permite inferir que essas famílias priorizavam o trabalho e em muitos casos, saber ler e escrever era considerado suficiente para atender à vida prática (PORTES, 2001; VIANA, 2009). 
Quanto à ocupação, segundo os relatos, na época, a maioria dos pais era autônoma e exercia (ou exerce) profissões consideradas de baixa remuneração e pouco prestígio social (jardineiro, caminhoneiro, escultor/artesão) e as mães exerciam, predominantemente, atividades remuneradas ligadas a trabalhos domésticos. Para Lahire (1997), essas são características comuns nas camadas populares e o que pode definir diferentes destinos escolares no mesmo meio social, são as vivências no âmbito familiar.

A longevidade escolar e os empregos dos filhos, que exigem Ensino Superior, concursos públicos, entre outros, demonstram que, entre os estudantes entrevistados e seus irmãos, além de maior escolaridade, há uma tendência de ascensão socioeconômica dos filhos em relação aos pais. Percebe-se claramente essa situação na família da Camila, estudante de Medicina, cujos pais cursaram somente o Ensino Fundamental. Durante a entrevista, Camila relata que " $a$ [irmã] que tem curso superior completo é advogada, 36 anos, e a que tem segundo grau trabalha em escola primária". (Camila, 8o período, Medicina).

Conforme observado por Gabriela, aluna da Engenharia Civil, uma das explicações para esse fenômeno pode estar vinculada às exigências de mercado, que impulsionam obrigatoriamente as pessoas a procurarem por maior formação educacional.

Nos relatos observa-se ainda que as atividades de lazer eram restritas nos meios familiares dos entrevistados. Sair da rotina e divertir, para alguns desses estudantes era ir à casa dos avós nos finais de semana. A falta de práticas culturais (como viajar, ir ao cinema, teatro, shows e a outros eventos), conforme observado também por Portes (2001) e Nogueira (2011) em suas pesquisas, é comum nos meios populares e pode ser compreendida pelas condições de origem social modesta, sobrecarga de trabalho, salários insuficientes, falta de oportunidade e de contato com a cultura dominante.

Atualmente, segundo os relatos, nenhum dos entrevistados mora com a família, e somente um deles tem vínculo empregatício. A maioria, além do apoio familiar, depende de bolsas institucionais para se manter na universidade.

Prosseguindo as análises, na sequência serão apresentadas as informações sobre o percurso escolar desses estudantes. 


\section{Percurso escolar}

Nessa pesquisa, verificou-se que a maioria dos entrevistados iniciou seus estudos com idades entre cinco e seis anos, cursou toda a educação básica, segundo seus depoimentos, em boas escolas públicas e nenhum deles obteve qualquer tipo de reprovação durante esse período escolar. Essa situação é considerada atípica nos meios populares, principalmente se considerarmos variáveis como a escolarização e ocupação dos antecessores, a condição econômica familiar e a proximidade com a cultura dominante (PORTES; LOPES e SILVA, 2011; VIANA, 1998, 2009; PIOTTO, 2007 entre outros). Cabe ressaltar que a Jéssica cursou parte do Ensino Fundamental em escola particular, o que nos retrata uma prática cada vez mais comum nas camadas populares. Os pais se esforçam para manter seus filhos em escolas particulares, principalmente durante o Ensino Fundamental, visando garantir um futuro escolar mais promissor (NOGUEIRA; NOGUEIRA, 2015).

Vários estudos revelam que a participação efetiva dos pais no processo de escolarização dos filhos é fator preponderante para obtenção de um bom resultado. Porém, sob a percepção dos entrevistados, essa participação foi pequena. Na maioria das vezes, somente as mães participavam das reuniões escolares. Camila contava com a ajuda do padrasto em relação aos deveres de casa; Henrique declarou que a mãe o ajudava com as tarefas escolares, quando necessário e Gabriela informou que obteve auxílio da mãe somente antes de aprender a ler. Sob a lembrança de um passado difícil, Pedro reclamou sobre a ausência de seus pais em seu cotidiano escolar:

Não queria ser injusto com eles, mas eles nunca participaram. Meu pai parou de ajudar mesmo na educação na 5a série. Então, meu pai, como ele só tem até a $4 \stackrel{a}{a}$ série, para ele bastava você saber ler, multiplicar, dividir, somar, subtrair [...] Então foi minha mãe que manteve a gente na escola depois da 4⿳a série, nem tanto visando a faculdade, mas visando colocação no mercado de trabalho (Pedro, 8o período, Medicina).

Embora Pedro afirme o contrário, podemos perceber que a participação dos pais na vida escolar desse estudante se fez presente. Mesmo a ausência de práticas familiares, na avaliação de Viana (2009), também pode ser considerada uma forma de mobilização escolar familiar. Nesse contexto, geralmente encontram-se pais que se sacrificam para apoiar financeiramente e garantir 
os estudos dos filhos; avós que cuidam dos netos para que os pais possam trabalhar; filhos com idade avançada que, até concluírem os estudos e se inserir no mercado de trabalho, se mantêm sob a tutela dos pais etc. (VIANA, 2009). É fato que, em pleno século XXI, ainda é possível verificar inúmeros casos de crianças e jovens que deixam os estudos para trabalhar ou mesmo de pais que não priorizam a educação escolar dos filhos, porque, conforme verificado por Portes (2001) e Viana (2009), a urgência da vida para essas famílias é atender as necessidades básicas.

Por outro lado, o Luan, em seu depoimento, afirmou que sua mãe, embora não participasse efetivamente de sua vida escolar, ela sempre o orientou para que buscasse "ser melhor". Essa situação reporta-nos à ordem moral doméstica (LAHIRE, 1997), em que as regras sociais julgadas convenientes são repassadas de pais para filhos. "Trata-se de um esforço contínuo que não tem como alvo específico o sucesso escolar, e, sim uma educação mais abrangente, uma educação para a vida" (PORTES, 2001, p.67). De certa forma, podemos verificar essa ordem moral doméstica presente na vida dos estudantes entrevistados. Todos, segundo seus relatos, apresentaram bom comportamento durante a educação básica, o que pode estar relacionado à existência do respeito pelo professor, ao conformismo diante das regras escolares e à organização.

Quando questionados sobre a educação básica, a maioria dos entrevistados julgou ter passado por boas escolas e teceu elogios aos professores que tiveram, ressaltando a sua dedicação e competência na transmissão do conhecimento, com raras exceções. Para além da atividade profissional, Pedro também mencionou maior proximidade com alguns professores, que conversavam sobre vários assuntos do cotidiano, ensinavam aos alunos a tratar os outros com respeito, manter o uniforme limpo e o material escolar em ordem. O depoimento de Gabriela corrobora essa proximidade com os professores: "[...] mesmo questão pessoal já conversei com professor, às vezes a gente num desabafa com o pai, mãe, a gente acaba desabafando com alguma outra pessoa, tem alguns professores que a gente tem mais afinidade, aí acabava conversando" (Gabriela, 6o período, Engenharia Civil). Na avaliação de Portes (2014) e Piotto (2014), os professores são referências positivas, e, principalmente para os estudantes pobres, se constituem em uma importante ponte de interação com o mundo e fonte de inspiração, podendo exercer forte influência no destino escolar do estudante, o que podemos constatar mais uma vez na fala da Gabriela: 
Eu fiz o curso técnico de edificações no IF [Instituto Federal]. Então eu escolhi Engenharia Civil pra poder continuar na área, porque eu gostei do curso técnico, e eu gostava muito de um professor também. Eu me espelhei nele, e ele é engenheiro civil. E eu gostava muito de uma professora de matemática, engenheira civil também. Aí eu optei pela engenharia. [...] falavam pra eu tentar Engenharia Civil, que é muito bom, e eu tenho vontade de ser professora um dia. Então por me espelhar neles e ver que eles formaram em Engenharia Civil, eu quis (Gabriela, 6o período, Engenharia Civil).

Na entrevista, Gabriela revela que, durante a educação básica, mantinha um bom relacionamento com os professores, mas teve problemas de ciúmes por parte de algumas colegas: "[...] Tive problema no Ensino Fundamental, meninas assim, com inveja porque eu era aplicada, que a professora elogiava. Aí ficavam com ciúmes e acabavam brigando comigo, mas nada que ... meu pai foi lá na época, conversou e deu tudo certo" (Gabriela, 6o período, Engenharia Civil). Essa situação não é rara entre os estudantes de camadas populares, em que, paradoxalmente, aqueles com elevado desempenho acadêmico ganham aproximação dos professores e são renegados pelos colegas de turma (LACERDA, 2006).

Embora todos os entrevistados tenham apresentado bom desempenho no Ensino Fundamental, a maioria apresentou dificuldades ao ingressar no Ensino Médio relacionadas ao aumento da responsabilidade, exigências de um nível escolar mais avançado e ao processo de adaptação ao novo modelo de estudo.

A diferença é muito grande, as possibilidades, carga horária de aula, acho que isso influencia muito. E a questão também de você ter que aprender a disciplina por conta própria, porque querendo ou não, os professores, a maioria deles, te dão o norte e você tem que se aprofundar (Henrique, $7^{\circ}$ período, Direito).

Outra revelação interessante dos estudantes entrevistados foi a mudança dos hábitos de leitura à medida em que avançavam nos estudos. Durante a infância e adolescência, seus gostos variavam de gibis a romances espíritas, que conseguiram, em certa medida, transformar em contribuição para o seu aprendizado. Entre os jovens das camadas populares, poucas vezes têmse o contato com grandes obras literárias, textos científicos etc. A leitura não se insere de maneira semelhante entre os diversos grupos sociais, pois há, de um lado as preferências e do outro as disponibilidades econômicas e culturais dos indivíduos. Além disso, as escolas de educação básica mais elitizadas proporcionam melhor interação de seus alunos com a leitura, 
com orientação de profissionais mais capacitados e acesso a obras mais interessantes, o que difere muito do padrão de acesso e da literatura recomendada pela escola frequentada pelas classes sociais menos favorecidas. Para compreender a influência da leitura na formação do jovem de camadas populares com longevidade escolar e a apropriação das informações pelos mesmos, recorremos à obra de Setton (2005). A autora alerta para as outras formas familiares de cultura geral, entendida não só como a cultura escrita, mas como a cultura visual, midiática, a cultura da rua e das vivências experimentadas virtualmente e que ganharam espaço entre os jovens. A maioria dos estudantes entrevistados capitalizaram informações de forma diferenciada, sem muito rigor e qualidade e atualmente, se dedicam apenas às leituras acadêmicas, justificadas pela falta de tempo.

Todas essas disposições pessoais e familiares apresentadas até aqui, constituem a preparação desses sujeitos para a vida universitária, delineada por novas experiências.

\section{Experiências universitárias}

Para ingressar na UFOP, cada estudante aqui pesquisado apresentou uma situação diferente. Dois deles fizeram o curso preparatório e foram aprovados no primeiro processo seletivo que participaram. Outros três já tinham alguma experiência com o ensino superior, sendo que um já lograva um título de especialização. Este último foi o que mais participou de processos seletivos. Somente para o curso de Medicina tentou sete vezes, sendo a última pelo SiSU, a UFOP era sua 2a opção. Sofia ingressou pelo processo de reopção.

Adaptar-se ao meio universitário exigiu um pouco mais desses estudantes.

Num primeiro momento, o receio. Quando você entra na turma e as pessoas vão se apresentando, são todos filhos de médico, tem muito filho de médico, muito filho de empresário, a gente se sente um pouco excluído por vir de uma classe social mais baixa [...] Superado esse obstáculo, veio a questão financeira, da bolsa, essas preocupações todas. Tem a moradia, eu não fui o único que mudei de casa várias vezes [...] O clima da cidade, tem muita gente que não se adapta ao clima da cidade (Pedro, 8o período, Medicina).

[...] minha sala tem muita gente do Bernoulli, Mackenzie, gente que veio de particular, e eu sou de escola pública. Eu não tinha uma boa rotina de estudo, como estudar, pegar e sentar pra estudar, não tinha, e isso aos poucos que eu fui aprendendo, pegar um livro... Porque eu vou em todas as aulas, não tenho

Periódico Horizontes - USF - Itatiba, SP - Brasil - e021010 
nenhuma falta em nenhuma matéria, tenho tudo copiado que o professor passa na sala e tudo mais. Só que chega na prova eu vou mal, eu posso estudar, sentar cinco horas estudando mas chega na prova eu vou mal, eu não sei o que acontece. Isso me deixa muito triste. Aí quando a gente vai indo mal, vai sendo reprovada nas matérias, a gente vai desanimando, a gente pensa em desistir, pensa em sair. E eu vejo que alguns professores dão a nota de acordo com o perfil do aluno, não sei, eu vejo que tem alguns professores que sim, não são todos (Sofia, 5o período, Direito).

O processo de adaptação e filiação ao novo ambiente educacional também requer do estudante equilíbrio físico e mental, conforme observa Gabriela "[...] no início foi difícil, eu até fiz acompanhamento com a psicóloga do posto. Aí algumas vezes eu fui lá conversar com ela, porque eu me sentia muito sozinha, mas agora eu já superei isso" (Gabriela, 6o período, Engenharia Civil).

Esses depoimentos revelam situações de conflito, vivenciadas por esses estudantes, dadas as diferenças sociais e a baixa qualidade de ensino na educação básica. Logo no início, conforme verificado por Souza (2016), surgem as primeiras dificuldades para compreender e acompanhar as discussões e reflexões, desenvolver e produzir o pensamento cientificamente, 0 que acaba influenciando negativamente a autoestima, a motivação e o interesse desses estudantes. Segundo Coulon (2008), devido às mudanças radicais que ocorrem no âmbito familiar, afetivo e psicopedagógico, é comum que os estudantes ingressantes se sintam solitários, até que comecem a conhecer e a se adaptar ao ambiente e aos códigos universitários. Na percepção de Piotto (2014), as maiores dificuldades podem estar atreladas à convivência com a desigualdade social, sobretudo quando esse estudante de baixa renda se insere em um curso de alto prestígio.

De fato, os estudantes entrevistados apontaram a questão financeira como o maior problema enfrentado durante a permanência na universidade, seguido da adaptação à moradia, o que pode ser verificado na fala do Henrique: "Até hoje a única coisa que me preocupa ainda é essa questão de me manter financeiramente, então é meio que um fantasminha que sempre fica lá no fundo, sabendo que eu tenho, além da universidade, essa responsabilidade pra ficar atento" (Henrique, $7^{\circ}$ período, Direito).

Para além dos estudos, os gastos com alimentação, aluguel, transporte, material didático etc., são preocupações constantes para esses estudantes. Pesquisadores como Portes (2001), 
SOUZA (2009) e Batista (2016) também identificaram o alto impacto das necessidades econômicas no percurso universitário de jovens de baixa renda.

Em relação à moradia, com exceção da Gabriela, que morava em um quarto individual do alojamento da instituição por apresentar problemas de sociabilidade, os demais dividiam residência com outras pessoas, em grande parte, também estudantes. Segundo consta em seus relatos, a maioria dos entrevistados já teria passado por diversas moradias, devido a problemas pessoais, do local, de convivência com os coabitantes ou vizinhos, o alto valor do aluguel etc. Henrique, morador de república, acrescentou a dificuldade de dividir os estudos com os afazeres da casa. Para Portes (2014), a situação da moradia está diretamente relacionada às condições econômicas dos estudantes e aparece como um elemento prioritário para a sua estabilidade.

A pesquisa também possibilitou detectar atitudes de discriminação e de preconceito.

Existe um bom relacionamento, mas uma divisão em questões sociais eu acho. Acredito que não existe essa divisão explicita em relação a cota em si, mas eu acho que por questão de afinidade, as pessoas de um nível social têm mais afinidade com pessoas do mesmo nível (Camila, 8o período, Medicina).

Eu tenho vergonha de chamar eles [para estudar em grupo], ainda mais tendo notas ruins. [Ajuda] Nunca foi negada, mas me enrolaram (Sofia, 5o período, Direito).

[...] A gente as vezes tem um receio que acho que parte da gente mesmo, porque não é o mesmo universo. Quando você participa de uma discussão dessa [colega discutindo sobre não poder viajar pro exterior], eu nunca tive no exterior, a gente se sente um pouco excluído. Você vai conversar com uma pessoa dessas, o assunto não flui com o nosso, as preocupações que eles têm não são as mesmas nossas. Então isso afasta um pouco, mas não por eu ser cotista, o mundo que eu fui criado que é muito diferente do deles (Pedro, 8 período, Medicina).

Tais depoimentos revelam situações de discriminação e de preconceito, às vezes ocultas, que podem incutir no estudante pobre o sentimento de não pertencimento àquele lugar, levando-o ao isolamento e à solidão. Para Piotto (2014, p.144), às vezes, "a discriminação pode ser sutil, o que torna sua compreensão e o seu enfrentamento mais difíceis e sofridos por parte daquele que a sofre".

Verificou-se, também, que as atividades acadêmicas desenvolvidas com os colegas se limitam aos trabalhos que precisam ser feitos em grupo e que, mesmo assim, na maioria das vezes, são realizados via internet. Pedro ressaltou que, no início do curso, os estudantes se 
reuniam com frequência, principalmente nos finais de semana para estudar e tirar dúvidas, mas, com o tempo e depois de alguns conflitos, essa prática foi diminuindo e hoje é "cada um por si".

Já as atividades de lazer parecem quase inexistentes. Somente José e Henrique citaram uma ida a um barzinho e um passeio ecológico de vez em quando para aliviar as tensões advindas do cotidiano universitário. Causa-nos surpresa a vida voltada somente para os estudos, que a maioria dos alunos entrevistados afirmou levar, considerando que as repúblicas universitárias de Ouro Preto são famosas for suas festas frequentes e a cidade oferece inúmeros eventos culturais gratuitos ao longo do ano. A explicação para a falta de práticas culturais entre esses estudantes pode estar vinculada à condição socioeconômica e ao sentimento de não pertencimento ao meio universitário. Segundo avaliação de Piotto (2014), muitos estudantes pobres não têm amigos no local onde residem e também não possuem tempo e condições materiais favoráveis para participarem de festas, e irem a bares ou clubes, onde poderiam cultivar novas amizades. Além disso, não carregam consigo o gosto por eventos culturais, dada as condições da vida pregressa desse estudante.

Diante das dificuldades econômicas, a maioria dos estudantes entrevistados afirma que busca diferentes alternativas para complementar a contribuição financeira familiar e arcar com suas despesas básicas, sem criar vínculos empregatícios. A principal estratégia utilizada por eles é a adesão aos Programas de Assistência Estudantil (auxílios, alimentação, moradia e saúde). É o que nos revela a fala da Gabriela: "Eu acredito que seria muito difícil de eu conseguir permanecer aqui na universidade sem o auxílio [da UFOP] que eu tenho, sem moradia, sem alimentação, acharia muito difícil" (Gabriela, 6o período, Engenharia Civil).

Emerge também, como alternativa bastante significativa, tanto do ponto de vista financeiro como do enriquecimento curricular, a participação em Programas Acadêmicos, a que denominamos de "oportunidades" extracurriculares ou acadêmicas. A UFOP disponibiliza aos estudantes regularmente matriculados, programas de pesquisa e de extensão, mobilidade acadêmica, auxílios de participação em eventos etc. desde que atendam aos critérios estabelecidos em editais específicos, como por exemplo, possuir coeficiente igual ou maior que seis. Todos os sujeitos da pesquisa revelaram já terem participado de alguma atividade extracurricular, remunerada ou não, conforme relacionado no Quadro 2. 
Quadro 2: Atividades extracurriculares empreendidas pelos estudantes entrevistados durante o percurso

universitário

\begin{tabular}{l|l}
\hline Estudantes & Atividades extra curriculares (remuneradas ou não remuneradas) \\
\hline Gabriela & $\begin{array}{l}\text { Monitoria } \\
\text { Iniciação científica }\end{array}$ \\
\hline \multirow{3}{*}{ José } & $\begin{array}{l}\text { Iniciação científica } \\
\text { Monitoria } \\
\text { Seminários (participação e organização) } \\
\text { Participante da Federação Estadual de Engenharia Civil }\end{array}$ \\
\hline \multirow{3}{*}{ Sofia } & $\begin{array}{l}\text { Jovens Talentos para a Ciência } \\
\text { Projeto de extensão }\end{array}$ \\
\hline \multirow{3}{*}{ Henrique } & $\begin{array}{l}\text { Apresentação de trabalho em evento } \\
\text { Estágio não obrigatório }\end{array}$ \\
\hline Camila & $\begin{array}{l}\text { Iniciação científica } \\
\text { Apresentação de trabalho em evento } \\
\text { Grupo de estudo } \\
\text { Jovens Talentos para a Ciência }\end{array}$ \\
\hline \multirow{3}{*}{ Pedro } & Grupo de estudos \\
\hline & $\begin{array}{l}\text { Jovens Talentos para a Ciência } \\
\text { Congresso internacional } \\
\text { Organização de congressos regionais } \\
\text { Grupo de estudos }\end{array}$ \\
\hline
\end{tabular}

Fonte: Elaborado pelos autores

Considerando o Quadro 2, é notória a ausência dos indivíduos pesquisados nos intercâmbios nacionais e internacionais. E esse fenômeno seria decorrente da falta de oportunidade ou da falta de interesse? Os estudantes elencaram diferentes motivos.

[...] mobilidade acadêmica, quando aparece no site da UFOP eu tenho conhecimento, mas não tenho vontade de participar, até mesmo porque agora que eu comecei a fazer o inglês. Vai fazer um ano e meio que eu estou fazendo o inglês (Gabriela, 60 período, Engenharia Civil).

Eu não tinha interesse porque eu já entrei na faculdade de medicina um pouco velho, e como o curso é muito longo e a permanência em Ouro Preto não é tão fácil, eu pensava mais nisso: em vir pra cá e terminar o curso. Então, não tentei intercâmbio em virtude disso, quando é que eu vou sair da faculdade, e esse um ano fora, como é que pode me atrapalhar (Pedro, 8o período, Medicina).

Sim. Portugal. Meu sonho é ir pra Portugal, pra eu saber como é a lei lá, como é aplicada, mas infelizmente para o direito não tem, aí teria que ter dinheiro. Tem até o (intercâmbio) da Caint [Coordenadoria de Assuntos Internacionais], mas tem que ter dinheiro (Sofia, 5o período, Direito). 
Em todas as situações relatadas sobre a não participação de uma mobilidade acadêmica, vê-se claramente o peso das disposições socioeconômicas dos estudantes: a falta de um curso de língua estrangeira; a necessidade de conclusão do curso para ascensão financeira que a titulação pode proporcionar, além de que o atraso no curso significaria mais despesas; a falta de condições financeiras para arcar com os gastos de um intercâmbio; e o sentimento de não pertencimento àquele grupo, seja por diferença de idade ou de condições socioeconômicas e/ou culturais.

Os depoimentos abriram possibilidades para a reflexão sobre as atividades extracurriculares oferecidas na universidade que os estudantes pobres podem aderir ou não. Certamente, atividades como mobilidade acadêmica, que exigem maior participação financeira das famílias, não estão entre as principais opções para esses jovens. Contudo, todas as oportunidades de realização de atividades que oferecem bolsas de estudos ou que não exigem gastos extras são potencialmente aproveitadas por eles. A participação de estudantes de meios populares em programas acadêmicos também foi registrada nos estudos de Portes (2001), Falcão (2012) e Batista (2016) como estratégia para ampliarem seus conhecimentos e concomitantemente como fonte de renda para se manterem na universidade.

Questionados sobre as principais mudanças ocorridas a partir do ingresso no ensino superior, a maioria enfatizou o amadurecimento, a independência pessoal, a possibilidade de conhecer e conviver com pessoas diferentes. Para Gabriela, a principal mudança foi ter "acordado para a vida". Henrique ressaltou a contribuição da universidade para seu amadurecimento pessoal, o aumento do senso crítico, aprender a enxergar a sociedade e perceber "como as coisas funcionam". Tanto Gabriela quanto Camila se sentem fonte de inspiração para que seus familiares valorizem a educação e prorroguem seus percursos escolares.

Cabe ressaltar que a maioria dos estudantes entrevistados foi enfática ao atribuir à Política de Ação Afirmativa a oportunidade de ingressarem e prosseguirem seus estudos na universidade pública.

Eu acho essencial, acho muito importante, porque não tem como comparar o ensino público com o ensino privado [...] no ensino público a gente não tem a oportunidade de conhecimento que o ensino privado tem, e tem vários outros fatores que influenciam isso [...] Eu acho que tem que existir sim essa política de ação afirmativa em conjunto com medidas para melhorar o ensino [básico] público (José, 7o período, Engenharia Civil). 
Nos depoimentos, foi possível verificar que a exclusão dos estudantes cotistas se manifesta de uma maneira velada, corroborando com a tese dos "excluídos do interior" (BOURDIEU; CHAMPAGNE, 2013), que evidencia e mantem a segregação social no interior da escola, fazendo com que

[...] o sistema de ensino, amplamente aberto a todos e, no entanto, estritamente reservado a alguns, consiga a façanha de reunir as aparências da "democratização" com a realidade da reprodução, que se realiza em um grau superior de dissimulação, portanto com um efeito acentuado de legitimação social (BOURDIEU; CHAMPAGNE, 2013, p.250).

Contudo, os estudantes entrevistados seguem confiantes em seus diplomas. Segundo os depoimentos, a maioria pretende se inserir no mercado de trabalho tão logo terminem a graduação. José e Gabriela preferem se dedicar a um mestrado antes de atuarem profissionalmente. Todos os estudantes entrevistados são movidos pela forte vontade de ter uma carreira de sucesso, ascensão social e condições financeiras favoráveis que lhes proporcionem uma vida mais tranquila.

\section{Considerações finais}

Essa pesquisa traz importantes considerações sobre o percurso acadêmico de estudantes de baixa renda no ensino superior e evidencia conflitos advindos do aumento da presença desses sujeitos numa universidade pública, principalmente em se tratando de cursos de alto nível socioeconômico.

A partir das entrevistas foi possível verificar que esses estudantes superselecionados (BOURDIEU, 2013) em cursos de alto prestígio, construíram percursos escolares improváveis diante das desigualdades sociais, principalmente tendo em vista a escolarização das gerações precedentes, a ocupação dos pais, a condição econômica familiar e a aproximação com a cultura dominante. Embora nenhuma família dos estudantes entrevistados tenha apresentado um projeto intencional de escolarização longeva dos filhos, nem mesmo para os estudantes de Medicina, em que essa prática é quase uma regra, verificou-se que indiretamente todos contaram com o apoio familiar, seja liberando das tarefas domésticas e da contribuição 
financeira, mantendo o filho na escola etc. As mães foram as que mais incentivaram os estudos, visando ascensão profissional e à melhoria de vida futura.

Apesar de apresentarem uma trajetória escolar linear, sem reprovações e retenções na educação básica, os entrevistados relataram certa dificuldade no início do curso superior, o que pode ser consequência da qualidade da educação básica, da alteração do ritmo e da rotina de estudos, além dos processos de adaptação ao meio universitário e à moradia, às desigualdades socioeconômicas e à dificuldade de socialização. Conforme já apontado pela literatura, as dificuldades financeiras constituem o maior desafio para continuar na universidade, e para a maioria, as bolsas assistenciais e acadêmicas é um meio de sustento e garantia de permanência na instituição.

Considerando que estamos tratando de cursos de alto prestígio, o isolamento social, verificado em grande parte das entrevistas realizadas, parece funcionar como um escudo de proteção às diferenças advindas de suas condições sociais, culturais e econômicas. Há um considerável distanciamento entre os estudantes pobres e os estudantes de camadas mais elevadas, o que gera certos conflitos. A discriminação e o preconceito, mesmo disfarçados em sua sutileza fazem parte do cotidiano desses estudantes, o que deve ser combatido pela comunidade universitária, considerando que este é um lugar de unir as diversidades, sejam elas culturais, sociais, econômicas etc.

E para vencer tantas adversidades é necessário um grande esforço, principalmente daqueles de menor poder econômico. Há um alto grau de responsabilização, por parte dos estudantes entrevistados, pelo seu destino escolar, o que requer elevado investimento pessoal e autodeterminação.

Outra revelação importante é que os cotistas também agregam, em seus currículos, atividades de pesquisa, extensão, monitoria, entre outras, que, muitas vezes, além da importante contribuição financeira, constituem oportunidades de crescimento acadêmico, cultural, pessoal e profissional.

Em síntese, foi possível concluir que, embora apresentem certa dificuldade financeira, acadêmica e de sociabilidade ao ingressar no Ensino Superior, os estudantes cotistas de baixa renda, mediante esforço e determinação, logo se tornam estudantes universitários nos termos de Coulon (2008), desbravando as oportunidades e os desafios do meio universitário e se 
equiparam academicamente aos demais estudantes da ampla concorrência.

As políticas de ação afirmativa têm contribuído para a inclusão de estudantes de meios desfavorecidos no ensino superior, mas ainda se faz necessário melhorias na educação básica e uma política de atendimento voltada para esses estudantes para que eles possam dar continuidade aos estudos de forma mais tranquila.

Embora esse estudo se limite à UFOP e a uma amostra pequena de entrevistados, a pesquisa analisa casos que podem, muito provavelmente, ser encontrados em outras IPES que adotaram as cotas no processo seletivo. De qualquer forma, mais estudos são necessários para aprofundar o entendimento sobre o percurso universitário de alunos pobres. Os relatos dos jovens entrevistados, trazem contribuições importantes para a reflexão a respeito de suas experiências e dificuldades vivenciadas ao longo do seu percurso universitário, contribuindo para o debate sobre a necessidade de implementação de políticas de combate ao preconceito e à discriminação e maior atenção a esse público carente de recursos para manter-se estudando. Também se faz necessária uma política pedagógica de nivelamento no início do curso, que torne mais branda as diferenças educacionais para a maioria desses indivíduos que não tiveram acesso a uma educação básica de qualidade. As políticas de ampliação das oportunidades de acesso e de permanência no ensino superior foram um grande passo para a inclusão das camadas populares nesse nível de ensino, mas ainda falta muito para que se possa atingir a verdadeira democratização do ensino no país, principalmente no tocante à permanência dos alunos na universidade.

\section{Referências}

BATISTA, N. M. L. Trajetórias de sucesso escolar de jovens oriundos de escolas públicas no ensino superior. 2016. 185f. Dissertação (Mestrado em Educação) - Universidade Federal da Paraíba, 2016.

BOURDIEU, P.; CHAMPAGNE, P. Os excluídos do interior. In: NOGUEIRA, M. A.; CATANI, A. (orgs.). Escritos de Educação. 14. ed. Petrópolis: Vozes, 2013, p.243-255.

BOURDIEU, P. A escola conservadora: as desigualdades frente à escola e à cultura. In: NOGUEIRA, M. A.; CATANI, A. (orgs.). Escritos de Educação. 14. ed. Petrópolis: Vozes, 2013. p.43-72.

BRASIL. Lei no 12.711, de 29 de agosto de 2012. Dispõe sobre o ingresso nas universidades 
federais e nas instituições federais de ensino técnico de nível médio e dá outras providências. Brasília, 2012.

BRASIL. Lei $n^{\circ} 13.409$, de 28 de dezembro de 2016. Altera a Lei $n^{\circ} 12.711$, de 29 de agosto de 2012, para dispor sobre a reserva de vagas para pessoas com deficiência nos cursos técnico de nível médio e superior das instituições federais de ensino. Brasília, 2016.

COULON, A. A condição de estudante: a entrada na vida universitária. Trad. Georgina G. dos Santos e Sônia Maria R. Sampaio. Salvador: EDUFBA, 2008.

COUTRIM, R. M. E; PENA, M. A. C.; SOUSA, L. P. Ação afirmativa em foco: táticas e estratégias de candidatos para burlar a Lei de Cotas em uma universidade pública. Rev.Educ., PUC, Campinas, v.23, n. 2, maio/ago. 2018.

FALCÃO, B. L. Um diploma de doutor a não "herdeiros": um estudo sobre impactos de cursos de alto prestígio da UFMG para egressos das camadas populares. 2012. 130f. Dissertação (Mestrado em Educação) - Faculdade de Educação, Universidade Federal de Minas Gerais, Belo Horizonte, 2012.

INSTITUTO NACIONAL DE ESTUDOS E PESQUISAS EDUCACIONAIS ANÍSIO TEIXEIRA (INEP). Censo da educação superior 2010: resumo técnico. Brasília: INEP, 2012.

LACERDA, W. M. G. Famílias e filhos na construção de trajetórias escolares pouco prováveis: o caso dos iteanos. 2006. 417f. Tese (Doutorado em Educação) - Programa de Pós-graduação em Educação, Centro de Estudos Sociais Aplicados, Faculdade de Educação, Universidade Federal Fluminense, Niterói, 2006.

LAHIRE, B. Sucesso escolar nos meios populares: as razões do improvável. Trad. Ramon A. Vasques e Sonia Goldefer. São Paulo: Ática, 1997.

NOGUEIRA, C. M. M; NOGUEIRA, M. A. Os herdeiros: fundamentos para uma Sociologia do Ensino Superior. Educação e Sociedade, Campinas, v. 36, n.130, p.47-62, jan./mar. 2015.

NOGUEIRA, M. O. Pais professores e a escolarização dos filhos. 2011. 267f. Tese (Doutorado em Educação) - Programa de Pós-graduação em Educação: Conhecimento e Inclusão Social, Faculdade de Educação, Universidade Federal de Minas Gerais, Belo Horizonte, 2011.

PENA, M, A. C. Os caminhos dos estudantes participantes da política de ação afirmativa na Universidade Federal de Ouro Preto: suas oportunidades e desafios no Ensino Superior. 2017. 260p.Dissertação (Mestrado em Educação) - Departamento de Educação, Universidade Federal de Ouro Preto, 2017.

PIOTTO, D. C. As exceções e suas regras: estudantes das camadas populares em uma universidade pública. 2007. 361f. Tese (Doutorado em Psicologia) - Programa de Pós-graduação em Psicologia, Universidade de São Paulo, São Paulo, 2007. 
PIOTTO, D.C. Estudantes das camadas populares na USP: encontros com a desigualdade social. In: PIOTTO, D. C. (org.). Camadas populares e universidades públicas: trajetórias e experiências escolares. São Carlos: Pedro \& João Editores, 2014, p. 133-166.

PIOTTO, D. C; ALVES, R. O ingresso de estudantes das camadas populares em uma universidade pública: desviando do ocaso quase por acaso. Revista Educ. PUC-Campinas, Campinas, v.21, n.2, p.139-147, maio/ago. 2016.

PORTES, E. A. Trajetórias escolares e vida acadêmica do estudante pobre da UFMG: um estudo a partir de cinco casos. 2001. 267f. Tese (Doutorado em Educação) - Faculdade de Educação, Universidade Federal de Minas Gerais, Belo Horizonte, 2001.

PORTES, E. A. A vida universitária de estudantes pobres na UFMG: possibilidades e limites. In: PIOTTO, D. C. (org.). Camadas populares e universidades públicas: trajetórias e experiências escolares. São Carlos: Pedro \& João Editores, 2014, p.167-237.

PORTES, E. A; LOPES e SILVA, C. C. Os efeitos do capital cultural na distribuição dos privilégios universitários: o caso dos bolsistas de iniciação científica da UFSJ. Tempos e Espaços, Sergipe, v.6, p.57-62, 2011.

PORTES, E. A; SOUSA, L. P.O nó da questão: a permanência de jovens dos meios populares no ensino público superior. In: SANTOS, G. G.; SAMPAIO, S. M. R. (orgs.). Observatório da vida estudantil: universidade, responsabilidade social e juventude. Salvador: EDUFBA, 2013, p.59-79.

RODRIGUES, E. C.; MATOS, D. A. S.; FERREIRA, A. S. Nível socioeconômico e ensino superior: cálculo e aplicações. Avaliação, Campinas, 2017. [no prelo].

SETTON, M. G. J. Um novo capital cultural: pré-disposições e disposições à cultura informal nos segmentos com baixa escolaridade. Educação e Sociedade, Campinas, v.26, n.90, p.77-105, jan./abr. 2005.

SETTON, M. G. J. Experiências de socialização e disposições híbridas de habitus. In: DAYRELL, J. et al. (org.). Familia, escola e juventude: olhares cruzados Brasil-Portugal. Belo Horizonte: Editora UFMG, 2012, p.38-55.

SOUZA, I. Estudo, estudar, ser estudante no ensino superior: condições gerais imanentes e contexto socioeconômico cultural das classes populares. Revista Labor, v.1, n.16, p.112-136, 2016.

SOUZA, M. S. N. M. Do seringal à universidade: o acesso das camadas populares ao ensino superior público no Acre. 2009. 214 f. Tese (Doutorado em Educação) - Programa de Pósgraduação, Faculdade de Educação, Universidade Federal de Minas Gerais, Belo Horizonte, 2009.

SOUZA, M. S. N. M. Estudantes de origem popular nos cursos mais seletos a UFAC. In: PIOTTO, 
D. C. (org.). Camadas populares e universidades públicas: trajetórias e experiências escolares. São Carlos: Pedro \& João Editores, 2014, p.89-132.

SZYMANSKI, H. Entrevista reflexiva: um olhar psicológico sobre a entrevista em pesquisa. In: SZYMANSKI, H. (org.). A entrevista na pesquisa em educação: a prática reflexiva. Brasília: Plano, 2002, p.9-61.

VIANA, M. J. B. Longevidade escolar em famílias de camadas populares: algumas condições de possibilidade. 1998. 240f. Tese (Doutorado em Educação) - Faculdade de Educação, Universidade Federal de Minas Gerais, Belo Horizonte, 1998.

VIANA, M. J. B. Disposições temporais de futuro e longevidade escolar em famílias populares. Perspectiva, Florianópolis, v.27, n.1, p.195-215, jan./jun.2009.

Recebido em junho 2019.

Aprovado em dezembro 2020. 